\title{
"A coisa mais antiga de que me lembro" ou como resgatar o reino literário de Sophia: notas para uma reconstrução pedagógica do universo andreseniano
}

\author{
Elisama Soraia Sousa de Oliveira \\ Instituto Politécnico do Porto \\ https://orcid.org/0000-0001-8569-8548
}

[Recibido, 18 setembro 2020; aceptado, 26 novembro 2020]

\begin{abstract}
[Sousa de Oliveira, E. S. (2020). "A coisa mais antiga de que me lembro" ou como resgatar o reino literário de Sophia: notas para uma reconstrução pedagógica do universo andreseniano. Boletín Galego de Literatura, 57, "Estudos", 39-51]

DOl http://dx.doi.org/10.15304/bgl.57.7117
\end{abstract}

RESUMO A realização deste artigo resulta da conjugação de dois fatores: por um lado, da vontade de estudar os textos da Arte Poética de Sophia de Mello Breyner Andresen que, em tempos mais recentes, têm permanecido levemente esquecidos; por outro, tendo em conta, como afirmou $M^{a}$ Graciete Besse (1990), que os princípios da Arte Poética andreseniana se encontram "também nos textos em prosa" (p. 11), fazendo valer a "grande unidade temática e estilística" (Gomes, 2000, p. 11) que José António Gomes percebeu na obra da autora d'A Menina do Mar, levar a cabo um estudo comparativo que torne visíveis os reflexos dos preceitos da poética de Sophia na sua prosa narrativa destinada às crianças e jovens, apontando, de permeio, caminhos que evidenciam a utilidade pedagógica da leitura cruzada destes textos no âmbito da Educação Literária. Palabras Chave: Sophia de Mello Breyner Andresen; Arte Poética; Educação Literária.

ABSTRACT This article results from the conjugation of two factors: on the one hand, from the desire to study the texts of Poetic Art by Sophia de Mello Breyner Andresen, which in more recent times have remained slightly forgotten; on the other hand, taking into account, as $M^{a}$ Graciete Besse (1990) has stated, that the principles of the andresenian Poetic Art are "also found in the prose texts" (p. 11), making use of the "great thematic and stylistic unity" (Gomes, 2000, p. 11) that José António Gomes perceived in the oeuvre of the author of The Girl of the Sea, carry out a comparative study that makes visible the reflections of Sophia's poetic precepts in her narrative prose aimed at children and young people, pointing out, in between, paths that demonstrate the pedagogic utility of their comparative reading in the Literary Education field.

KEYwORDS Sophia de Mello Breyner Andresen; Poetic Art; Literary Education.

\section{O reino literário de Sophia: considerações prévias}

No panorama literário português, Sophia é vulto incontornável tanto no sistema literário consagrado quanto na literatura destinada preferencialmente a um público infantojuvenil, ao qual dedicou grande parte da sua produção 
narrativa. Ainda que, para a infância e a juventude, a escritora se tenha destacado maioritariamente enquanto prosadora - através de clássicos como $A$ Menina do Mar (1. ${ }^{\text {a }}$ ed. 1958), A Fada Oriana (1. ${ }^{a}$ ed. 1958), O Cavaleiro da Dinamarca (1. ${ }^{\mathrm{a}}$ ed. 1964), O Rapaz de Bronze (1. ${ }^{\mathrm{a}}$ ed. 1966) ou A Floresta (1. ${ }^{\mathrm{a}}$ ed. 1968) -, no que à literatura vocacionada ao leitor adulto diz respeito foram os poemas que a fizeram alcançar um lugar cimeiro no sistema literário português. Importa, por isso, lembrar que foi através do texto lírico que Sophia de Mello Breyner se deu a conhecer, tendo iniciado a sua carreira literária como poetiza, em 1940, na Cadernos de Poesia, revista que se pautava pelo ecletismo e autonomia relativamente a "escolas ou grupos literários, estéticas ou doutrinas, fórmulas ou programas. [porque] A poesia é só uma” (cit. por Martinho, 1991, p. 89): é, pois, fruto deste labor continuado com a poesia que emergem as suas Artes Poéticas.

Os cinco textos que compõem a Arte Poética de Sophia de Mello Breyner Andresen inscrevem-se na esteira de uma longa tradição teórica de reflexão acerca do fenómeno literário, particularmente do poético, que tem na Arte Poética de Aristóteles uma das suas primeiras manifestações. Não obstante, não é nosso propósito ocuparmo-nos do universo poético da autora d' $A M e$ nina do Mar, pretendemos, antes, analisar a forma como os preceitos enunciados nas suas Artes Poéticas se encontram refletidos na produção narrativa de Sophia destinada preferencialmente a crianças e jovens, uma vez que os seus textos narrativos adquirem nos programas de Português do Ensino Básico e Secundário português um lugar de destaque, do qual a poesia andreseniana, porventura injustamente, não goza.

Por conseguinte, ainda que Sophia - à semelhança de Horácio, Nicolas Boileau-Despréaux e Miguel Torga - tenha seguido a linha de ponderação relacionada com o fazer poético e os seus fundamentos estético-ideológicos, para levar a cabo o percurso que nos propusemos seguir neste estudo faremos uso de uma aceção mais abrangente de poética, pelo que recorreremos à definição apresentada por Marc Angenot, no Glossário da Crítica Contemporânea (1984). Segundo este autor, que convoca Todorov para demonstrar que o filólogo búlgaro usa o termo como sinónimo de "ciência" ou "teoria da literatura", a poética diz respeito ao "conjunto dos princípios estéticos [...] que guiam o escritor (não especialmente um poeta) na sua obra” (Angenot, 1984, p. 179). A definição de Angenot reverte-se ainda mais proveitosa para a presente análise se considerarmos, igualmente, que, como afirmou $\mathrm{M}^{\mathrm{a}}$ 
Graciete Besse (1990), os princípios da Arte Poética andreseniana se encontram "também nos [seus] textos em prosa" (p. 11), fazendo valer a "grande unidade temática e estilística” (Gomes, 2000, p. 11) que José António Gomes percebeu na obra de Sophia. Assim, conjugadas as contribuições dos autores mencionados, é possível delimitarmos a base formal em que nos sustentamos para a realização desta análise.

\section{A Arte Poética de Sophia na produção narrativa para crianças e jovens}

Sophia de Mello Breyner Andresen iniciou o texto de "Arte Poética III" - que corresponde, aliás, ao discurso que proferiu, em 1964, num almoço organizado pela Sociedade Portuguesa de Escritores, quando recebeu o Grande Prémio de Poesia pelo Livro Sexto - com a expressão que tomamos emprestada para o título desta comunicação: "A coisa mais antiga de que me lembro" (Andresen, 1964, s.p.).

Ora, isolado da frase que o acolheu, este conjunto de palavras parece propenso a adquirir -tal é o seu potencial evocador e o apelo ao imaginário que promove- o poder encantatório de uma fórmula introdutória passível de ombrear com o prolífico "Era uma vez", maioritariamente associado aos contos tradicionais. Por esse motivo, estamos em crer, poderia constituir um bom ponto de partida, se utilizado com intencionalidade pedagógica, para a planificação, por exemplo, de uma atividade de escrita de intenção literária. Contudo, a fecundidade deste sintagma nominal andreseniano vai muito além das observações efetuadas; nele descobrimos, igualmente, a interrogação que esteve na sua génese, ou seja: qual é a coisa mais antiga de que me lembro?

Se tentarmos meditar nas possibilidades de resposta a esta questão, efetuaremos, inevitavelmente, o caminho retrospetivo que ela reclama -talvez um caminho semelhante ao percorrido por Sophia -, o qual nos levará à constatação de que este movimento contemplativo nos obriga a olhar o passado, colocando-nos em confronto com aquele - ou aquilo - que outrora fomos. Do exposto se conclui que o efeito perlocutório da expressão "A coisa mais antiga de que me lembro" é fortalecido pelo poder evocador de memórias subjacente ao verbo lembrar, mas também pela configuração do grupo nominal "a coisa mais antiga". 
Não obstante, o exercício proposto por Sophia não é apenas o de olharmos para o passado, mas o de, olhando-o, descobrirmos o instante primordial onde se esconde a essência e a génese da "coisa mais antiga" (Andresen, 1964, s.p.). A importância deste retorno ao estado inicial reside no facto de, para a autora, este ser sempre o mais puro e, por isso, mais verdadeiro, pois não tem mácula, conserva a essência com que foi criado, pondo em evidência a comunhão entre os elementos naturais e cósmicos - ou divinos - que lhe deram forma. É esta verdade, este profundo entendimento das coisas físicas e metafísicas que Sophia procura, como refere em "Arte Poética I"1 "nas praias de mar verde, no azul suspenso da noite, na pureza da cal, numa pequena pedra polida, no perfume do orégão" (Andresen, 1962, s.p.). Partindo, pois, destas considerações preliminares, atentemos, agora, na leitura do passo inicial do texto "Arte Poética III", onde se integra a expressão que temos vindo a dilucidar:

A coisa mais antiga de que me lembro é dum quarto em frente do mar dentro do qual estava, poisada em cima duma mesa, uma maçã enorme e vermelha. Do brilho do mar e do vermelho da maçã erguia-se uma felicidade irrecusável, nua e inteira. Não era nada de fantástico, não era nada de imaginário: era a própria presença do real que eu descobria. Mais tarde a obra de outros artistas veio confirmar a objectividade do meu próprio olhar. Em Homero reconheci essa felicidade nua e inteira, esse esplendor da presença das coisas (Andresen, 1964, s.p).

De entre os inúmeros caminhos que estas palavras de Sophia nos poderiam levar a percorrer, optamos por destacar alguns dos elementos que tendo enformado a sua poética se revêm significativamente na prosa narrativa da autora, a saber: (1) o valor da memória, (2) a importância do olhar, alicerçada no deslumbramento provocado pela experimentação do real, (3) "a experiência das coisas" (Ceia, 1996, p. 13), para utilizar a expressão de Carlos Ceia, (4) a rejeição do artificialismo, sobretudo retórico, e (5) o engrandecimento dos elementos da natureza, apresentados como primordiais e imaculados.

\section{O valor da memória e a inexorabilidade do tempo}

Relativamente ao primeiro aspeto que destacamos - o valor da memória -, percebemos, pelo excerto anteriormente transcrito, que a memória se configura como uma espécie de portal do tempo, estabelecendo uma ligação entre

1 Texto que a autora publicou pela primeira vez, em 1962, na revista Távola Redonda e que, a partir de 1967, passou a integrar, com "Arte Poética II", a obra Geografia. 
o presente e o passado, através da qual o sujeito acede ao conhecimento de si e das coisas que o rodeiam ou rodearam. Fundado na matriz grega e lembrando, particularmente, a mitificação da Memória pelo poeta Hesíodo, este substantivo para Sophia permite entretecer o "tempo dividido" - expressão que dá título à coletânea de poemas No Tempo Dividido (1954) - ou, se se quiser, para utilizar um sintagma de ressonância proustiana, o tempo perdido. É, portanto, pela memória que percorremos e reconstruímos esse tempo que, por ser pretérito, já não está acessível.

Esta tentativa de reconstrução e, de certo modo, também de eternização do passado é bem evidente na narrativa "A Viagem", de Contos Exemplares (1970, 1. a ed.), quando a mulher, no decorrer da jornada, vai dando conta, ao olhar pela janela do carro, de que os "campos, pinhais, montes e rios fugiam para trás" (Andresen, 2004, 91). O homem e a mulher - personagens principais deste conto - estavam a perder os "rios, campos, montes" (p. 93), porque "As paisagens fugiam, puxadas para trás" (p. 93). Ao perceber que tudo quanto encontravam desaparecia, a mulher, numa dada altura da viagem, já na floresta e sem o carro, decide colher amoras, reservando algumas delas para um momento posterior. Contudo, quando ambos voltam a ter fome e se lembram de procurar as amoras no lenço onde as guardaram, reparam que "o lenço estava vazio" (p. 104).

Do exposto se depreende que, além da tentativa de eternização do passado, Sophia trabalhou nesta narrativa a inexorabilidade do tempo, transformando a jornada efetuada pelos protagonistas, como evidenciou Clara Rocha (2001) no estudo que realizou a propósito dos Contos Exemplares, numa "parábola da vida, viagem sem regresso onde tudo vai ficando para trás, tudo desaparece e tudo se vai perdendo, sem que possamos passar duas vezes iguais pelos lugares do vivido" (p. 76). Convém, também, não esquecer as referências efetuadas neste conto às "maçãs vermelhas" (p. 98), que encontramos, igualmente, na "Arte Poética III", e à "bilha de barro" (p. 99), material que Sophia convoca no texto I da sua Arte Poética.

Num plano de análise semelhante ao anterior, encontramos, novamente, evidências da memória como recetáculo de passados no conto "O Homem", particularmente, no excerto que se apresenta de seguida:

Mas enquanto seguia no passeio rodeada de ombros e cabeças, a imagem do homem continuava suspensa nos meus olhos. E nasceu em mim a sensação con- 
fusa de que nele havia alguma coisa ou alguém que eu reconhecia. Rapidamente evoquei todos os lugares onde eu tinha vivido. Desenrolei para trás o filme do tempo. As imagens passaram oscilantes, um pouco trémulas e rápidas. Mas não encontrei nada. E tentei reunir e rever todas as memórias de quadros, de livros, de fotografias. Mas a imagem do homem continuava sozinha: a cabeça levantada que olhava o céu com uma expressão de infinita solidão, de abandono e de pergunta. E do fundo da memória, trazidas pela imagem, muito devagar, uma por uma, inconfundíveis, apareceram as palavras: -Pai, Pai, por que me abandonaste? Então compreendi por que é que o homem que eu deixara para trás não era um estranho (Andresen, 2003, pp. 139-140).

Retomando o plano de exposição relativo à memória enquanto veículo de acesso ao passado, verifica-se, em alguns contos de Sophia, a emergência da nostalgia associada a este conceito. Veja-se a este respeito a seguinte passagem d'A Fada Oriana (1958, 1. ${ }^{\text {a }}$ ed.) correspondente à primeira fala da "velha muito velha" (Andresen, 2000, p. 8) que Oriana ajudava:

Que negra vida, que negra vida! Estou tão velha como o tempo e ainda preciso de trabalhar. E não tenho nem filho nem filha que me ajude. Se não fossem as fadas que seria de mim? Quando eu era pequena brincava na floresta e os animais, as folhas e as flores brincavam comigo. A minha mãe penteava os meus cabelos e punha uma fita a dançar no meu vestido. Agora, se não fossem as fadas, que seria de mim? Quando eu era nova ria o dia todo. Nos bailes dançava sempre sem parar. Tinha muito mais do que cem amigos. Agora sou velha, não tenho ninguém. Se não fossem as fadas que seria de mim? Quando eu era nova tinha namorados que me diziam que eu era linda e me atiravam cravos quando eu passava. Agora os garotos correm atrás de mim, chamam-me "velha, velha", e atiram-me pedras. Se não fossem as fadas que seria de mim? Quando eu era nova tinha um palácio, vestidos de seda, aios e lacaios. Agora estou velha e não tenho nada. Se não fossem as fadas que seria de mim? (Andresen, 2000, pp. 8-9).

Neste excerto, é visível a nostalgia que anteriormente mencionamos, mas também se percebe que "a coisa mais antiga" de que esta personagem se lembra está escondida na sua infância, a qual recorda como um tempo de felicidade, prosperidade e comunhão, não só com as pessoas (pela referência que faz à mãe e aos amigos), mas também com a natureza. $\mathrm{O}$ mundo relatado por esta personagem é aquele que Sophia de Mello Breyner Andresen descreve no término de "Arte Poética I", comparando-o a um reino onde a aliança, que outrora existiu entre os seres que o habitavam, foi quebrada. Este é, por isso, um reino dividido que já não "está ligado nem ao sol nem à lua nem a Ísis nem a Demeter, nem aos astros nem ao eterno" (Andresen, 1962, s.p.). 
Esse reino passou a ser "só aquele que cada um por si mesmo encontra e conquista, a aliança que cada um tece" (Andresen, 1962, s.p.), sendo por esse motivo comparado pela autora ao corpo de Orfeu despedaçado pelas fúrias. Neste sentido, através da palavra que utiliza para nomear as coisas, o poeta tem o poder de construir mundos, motivo pelo qual Sophia de Mello Breyner acredita que esse reino perdido pode ser restabelecido através da palavra poética, como se pode perceber a partir da leitura do poema em prosa "Ingrina", no qual o sujeito poético afirma o seguinte: "Ali se erguia intacta a coluna do primeiro dia [...]. É esse o tempo a que regresso [...]. E sobre a areia sobre a cal e sobre a pedra escrevo: nesta manhã eu recomeço o mundo" (Andresen, 2004, p. 447).

\section{Rejeição do artificialismo}

Também no capítulo "O Homem Muito Rico", de A Fada Oriana, ocorrem outras passagens semelhantes à da velha, mas protagonizadas pelas coisas que habitavam a sala do Homem. Tanto uma, quanto as outras servem um propósito maior, o de denunciar a injustiça e a aliança quebrada à qual Sophia se refere no texto "Arte Poética I". Se este reino, esta aliança com o mundo, é "vulnerável" (Andresen, 1962, s.p.), o escritor que sente, à semelhança de Sophia, "a felicidade nua e inteira" perante "o esplendor da presença das coisas" não poderá aceitar "a fatalidade do mal” (Andresen, 1964, s.p.) - para utilizar as palavras que a autora escreveu em "Arte Poética III". Do mesmo modo que testemunha a alegria emanada pelo mundo, o escritor não poderá ignorar o seu "espantoso sofrimento" (Andresen, 1964, s.p.). Para ilustrar o que mencionamos acerca da aliança quebrada e da necessidade de dar a ver, a partir do texto, quer o esplendor quer, também, o sofrimento do mundo, cremos que se lerão com bastante proveito os pedidos do espelho, da mesa e da cómoda da casa do Homem Rico:

-Oriana -pediu o espelho -, tira-me daqui. Eu estou sempre a ver, vejo tudo. Esta sala cheia de coisas, esta sala sem espaço, sem vazio, sem largueza, cansa e magoa os meus olhos de vidro [...] e depois a mesa disse: - Oriana, não podemos estar aqui. Não cabemos nesta sala. Nesta sala há coisas de mais. Estamos todos apertadíssimos. E somos coisas com feitios diferentes e não nos entendemos bem. Eu sou uma mesa antiquíssima; estava na sala de jantar de um convento. [...] Aqui sinto-me muito mal [...]. Depois falou a cómoda: - Sou uma cómoda muito bonita e muito antiga. Durante dois séculos morei no solar de uma quinta. Estava numa sala muito grande e quem entrava via logo como eu era bonita [...] (Andresen, 2000, pp. 18-21). 
Demorando-nos um pouco mais neste tópico relativo à resistência perante a "fatalidade do mal" (Andresen, 1964, s.p.) e à denúncia das fragilidades que assombram esse mundo feito de alianças quebradas, importa referir que o mal não está ausente do universo literário de Sophia, como o comprovam, por exemplo, a personagem Homem Importantíssimo, d' "O Jantar do Bispo", narrativa que integra a obra Contos Exemplares, ou a Grande Raia e os búzios, como se pode ver nesta passagem de $A$ Menina do Mar:

Mas eu não gosto nada da Raia e tenho medo dela. Ela detesta os homens e também não gosta dos peixes. Até as baleias têm medo dela [...]. Os búzios têm muito bom ouvido, ouvem tudo, são os ouvidos do mar. E ouviram as nossas conversas e foram contá-las à Raia que ficou furiosa e agora eu já não posso ir ,contigo. [...] A Raia ordenou aos polvos que não me deixassem passar. As rochas estão cheias de polvos escondidos que nós não vemos, mas que nos vêem e espiam cada um dos nossos gestos. Tenho que te dizer adeus para sempre. Amanhã já não volto aqui porque a Raia, para me castigar de eu ter querido fugir, decidiu que esta noite ao nascer da Lua serei levada pelos polvos, para uma praia distante, que eu não sei como se chama, nem onde fica. E nunca mais nos poderemos encontrar (Andresen, s.d., pp. 16-26).

Como não lembrar, também, este outro excerto do percurso da Fada Oriana e a reprimenda que lhe foi dada pela Rainha das Fadas pelo facto de Oriana ter sucumbido à vaidade:

Vai pela floresta e vê o mal que fizeste. Vê o que aconteceu aos homens, aos animais e às plantas que tu abandonaste. A olhar para ti esqueceste-te dos outros. Só tornarás a ter asas quando tiveres desfeito todo o mal que fizeste. Só tornarás a ter asas quando te esqueceres de ti a pensar nos outros (Andresen, 2007, p. 43).

\section{A experiência das coisas}

Existe, ainda, uma outra dimensão da memória que Sophia de Mello Breyner explora quer nos textos da Arte Poética quer na sua prosa narrativa, que se relaciona, parafraseando José Ribeiro Ferreira (2013), com a memória como fonte do saber. Esta modalização da memória associada à transmissão de conhecimento que vai sendo passado, desde tempos imemoriais, de geração em geração, é, sobremaneira, visível no primeiro texto de Arte Poética, no qual Sophia descreve, da seguinte forma, a visita que fez a uma loja de barros em Lagos: "Barro que desde tempos imemoriais os homens aprenderam a 
moldar numa medida humana. Formas que através dos séculos vêm de mão em mão" (Andresen, 1962, s.p.). Esta transmissão do saber, que é acumulado pela sucessiva experimentação da realidade e das coisas, manifesta-se, por exemplo, no conto $O$ Cavaleiro da Dinamarca, através do conhecimento que a personagem principal vai adquirindo acerca dos locais por onde passa, mas também é visível, por exemplo, em $A$ Floresta, na passagem em que o anão explica a Isabel a razão da sua inteligência:

Bem - respondeu ele - nós os anões vivemos quinhentos anos e assim temos tempo de ver muito, ouvir muito, pensar muito. E temos uma grande memória. Quando somos novos, velhos anões contam-nos tudo quanto viram, durante os cinco séculos da sua vida. E também nos contam tudo quanto os pais deles lhes ensinaram. É por isso que eu te posso contar histórias que se passaram há mais de mil anos. Além disso viajamos muito (Sophia, s.d., p. 25).

As palavras desta personagem permitem que se chame à colação um novo tópico que Sophia de Mello Breyner aborda na "Arte Poética V" e que diz respeito à influência, na sua produção escrita, da literatura oral tradicional. A autora refere, evocando, novamente, as suas memórias mais remotas, o seguinte: "Na minha infância, antes de saber ler, ouvi recitar e aprendi de cor um antigo poema tradicional português, chamado Nau Catarineta. Tive assim a sorte de começar pela tradição oral, a sorte de conhecer o poema antes de conhecer a literatura" (Andresen, 1989, s.p.). No caso Sophia de Mello Breyner Andresen, assim como no de outros autores - recordamos, apenas a título exemplificativo, o caso de José Saramago que ouviu, antes de saber ler, da sua avó Josefa as histórias tradicionais que foram o seu primeiro contacto com o mundo literário -, o contacto com a literatura deu-se, primeiramente, a partir dos textos de transmissão oral. Não admira, portanto, que nas suas obras preferencialmente destinadas a crianças e jovens surjam, amiúde, personagens aos quais atribui os dotes de um contador de histórias, como ocorre neste passo de $O$ Cavaleiro da Dinamarca:

Terminada a ceia começava a narração das histórias. Um contava histórias de lobos e ursos, outro contava histórias de gnomos e anões. Uma mulher contava a lenda de Tristão e Isolda e um velho de barbas brancas contava a lenda de Alf, rei da Dinamarca, e de Sigurd. Mas as mais belas histórias eram as histórias do Natal, as histórias dos Reis Magos, dos pastores e dos Anjos (Andresen, s.d., p. 9). 


\section{A importância do olhar e o deslumbramento pela Natureza}

Quase a terminar este texto, centrar-nos-emos, brevemente, na importância do ver e do ouvir, relacionada com o fascínio provocado pela tomada de consciência das coisas. No texto ao qual atribuiu o título "Arte Poética II", Sophia empreende uma delimitação do fenómeno poético, avançando com a seguinte definição de poesia: "a poesia é a minha explicação com o universo, a minha convivência com as coisas, a minha participação no real" (Andresen, 1963, s.p.). A conceção expressa pela autora retoma a ideia apresentada anteriormente do escritor como artífice da palavra, uma vez que a utiliza para nomear as coisas e recriar o mundo de acordo com o entendimento que guardou dele. Ao longo desse texto, Sophia refere, igualmente, alguns dos requisitos que, na sua opinião, este modo de fazer poético requer do escritor. Assim, a autora declara que a poesia lhe pede "que viva atenta, [...] que viva sempre, [...] que nunca se esqueça", pede-lhe a "inteireza" (Andresen, 1963, s.p.) do seu ser. Nos textos IV e V de Arte Poética, Sophia irá retomar estes princípios, reiterando a relevância da atenção e da escuta - a autora achegar a afirmar que "o poeta é um escutador" (Andresen, 1972, s.p.) -, que devem preceder e acompanhar o processo de escrita. Do exposto se conclui que, para Sophia, a escrita deve refletir a experimentação do mundo, a aprendizagem das coisas, "a presença" e "a perseguição do real", de que fala em "Arte Poética III", para assim poder retratar com justeza e verdade "a pedra, [...] a árvore, [...] o rio" (Andresen, 1964, s.p.).

Deste modo, a poesia pede ao escritor que descubra o mundo e faça dessa experiência a matéria a partir da qual constrói os seus textos. Por isso, o escritor tem de conseguir retratar o instante primeiro em que viu e viveu as coisas, o olhar inaugural sobre o mundo, que nada mais é do que o "recomeço do mundo", como escreveu no poema "Ingrina". A recriação desse olhar inaugural encontra-se, sobremaneira, refletida no conto A menina do Mar, quando o rapaz oferece à menina três presentes da terra - a rosa, o fogo e o vinho, que são, também, elementos recorrentes e fundamentais na escrita de Sophia - e ela descreve o que sente ao conhecê-los pela primeira vez. Quando cheirou a rosa, a Menina do Mar afirmou:

É um perfume maravilhoso. No mar não há nenhum perfume assim. Mas estou tonta e um bocadinho triste. As coisas da terra são esquisitas. São diferentes das coisas do mar. No mar há monstros e perigos, mas as coisas bonitas são alegres. $\mathrm{Na}$ terra há tristeza dentro das coisas bonitas (Andresen, s. d., p. 18). 
Quando o menino lhe mostrou um fósforo aceso, disse: "É um sol pequenino" (Andresen, s. d., p. 21). Por último, no instante em que provou vinho, declarou o seguinte:

É bom e é alegre. Agora já sei o que é a terra. Agora já sei o que é o sabor da Primavera, do Verão e do Outono. Já sei o que é o sabor dos frutos. Já sei o que é a frescura das árvores. Já sei como é o calor duma montanha ao sol (Andresen, s. d., p. 24).

O relevo atribuído por Sophia ao olhar relaciona-se, igualmente, com a “perseguição do real” (Andresen, 1964, s.p.) mencionada em "Arte Poética III", cujo fim seria a reunião do reino disperso, tão almejada pela autora, como a própria demonstra no primeiro texto de Arte Poética, ao declarar que "Nós procuramos reuni-lo, procuramos a sua unidade, vamos de coisa em coisa" com o intuito de criar uma nova "aliança com as coisas" (Andresen, 1962, s.p.). Este estado inicial de harmonia entre os seres e o cosmos é visível nos primeiros capítulos de A Fada Oriana, como também nas histórias de vida que o anão de $A$ Floresta conta a Isabel e, ainda, em Os Ciganos -narrativa breve que Sophia deixou inacabada e o seu neto, Pedro Sousa Tavares, terminou.

No caso deste último conto, a aliança com o mundo natural está associada à comunidade de ciganos que Ruy, o protagonista, conhece através de Gela. É pelo tempo passado nesta comunidade que Ruy irá aprender a respeitar as coisas, a unir-se a elas, recuperando a aliança perdida, como é possível comprovar através do excerto que se segue:

Tudo isto the parecia estranho. "Onde é que já se viu falar com uma pedra?", perguntou o rapaz a si mesmo. Mas depois pensou que não perderia nada em tentar. [...] Assim voltou à margem e avançou novamente. Desta vez muito devagar. - Bom dia, senhora pedra - disse muito baixinho, [...] - O meu nome é Ruy e sou um rapaz da cidade, nada habituado a atravessar ribeiros. Queria pedir-lhe licença para passar. É muito importante para mim chegar à outra margem” (Andresen \& Tavares, 2013, p. 38).

Nas páginas seguintes desta obra, o narrador confirma o reatar dessa aliança ao contar que "Ruy, agora que aprendera a respeitar o tempo e o espaço das coisas, descobria-se a fazer o que antes lhe parecia impossível" (Andresen \& Tavares, 2013, p. 43). 


\section{A reconstrução pedagógica do universo andreseniano: considerações finais}

Concluímos este estudo com a consciência de que a abordagem apresentada não poderia contemplar todos os aspetos de relevo relativos aos textos da Arte Poética de Sophia, contudo esperamos ter conseguido demonstrar, ainda que parcelarmente, que a realização de uma leitura cruzada das Artes Poéticas com a prosa narrativa de Sophia de Mello Breyner favorecerá e revitalizará a leitura e a compreensão dos textos desta autora. Consideramos, assim, que o valor pedagógico deste cruzamento de leituras se encontra subsumido nos seguintes aspetos: (1) no relevo atribuído à escuta e à observação atenta, tão necessárias não só à leitura (ao ato físico de ler e à sua compreensão) mas também à escrita de textos de intenção literária; (2) no facto de os textos IV e V de Arte Poética, através do testemunho de Sophia, proporcionarem um olhar interno sobre o processo de criação literária, fator que, cremos, se reveste de uma importância acrescida, pois as Artes Poéticas ensinam a pensar sobre o processo de escrita, a refletir sobre ele e, à medida que o tornam consciente, promovem uma aprendizagem mais significativa dos procedimentos que o envolvem, facto que levará, desejavelmente, ao aperfeiçoamento da escrita e do próprio raciocínio crítico; (3) no facto de as Artes Poéticas iluminarem alguns pontos dos textos narrativos de Sophia, ajudando a aceder ao seu significado e de permitirem, por isso, reunir o reino de Sophia, coisa a coisa, livro a livro, trazendo novas perspetivas de análise, renovando e esporando o lugar deste universo no sistema literário português.

\section{Bibliografia}

\section{Bibliografia ativa}

Andresen, S. M. B. (2004). Contos Exemplares. Figueirinhas.

Andresen, S. M. B. (2004). Ingrina. En Geografia. Editorial Caminho.

Andresen, S. M. B. (2000). A Fada Oriana. Figueirinhas.

Andresen, S. M. B. (s.d.). A Menina do Mar. Figueirinhas.

Andresen, S. M. B. (s.d.). A Floresta. Figueirinhas.

Andresen, S. M. B. (s.d.). O Cavaleiro da Dinamarca. Figueirinhas. 


\section{Bibliografia passiva}

Andresen, S. (1962). Arte Poética I. En Biblioteca Nacional de Portugal (2011), Sophia de Mello Breyner Andresen no seu tempo: Momentos e Documentos (Selecção, conteúdos e organização por Maria Andresen Sousa Tavares). http://purl.pt/19841/1/ galeria/artes-poeticas/arte-poetica-i1.html

Andresen, S. (1963). Arte Poética II. En Biblioteca Nacional de Portugal (2011), Sopbia de Mello Breyner Andresen no seu tempo: Momentos e Documentos (Selecção, conteúdos e organização por Maria Andresen Sousa Tavares). http://purl.pt/19841/1/ galeria/artes-poeticas/arte-poetica-ii1.html

Andresen, S. (1964). Arte Poética III. En Biblioteca Nacional de Portugal (2011), Sophia de Mello Breyner Andresen no seu tempo: Momentos e Documentos (Selecção, conteúdos e organização por Maria Andresen Sousa Tavares). http://purl.pt/19841/1/ galeria/artes-poeticas/arte-poetica-iii.html

Andresen, S. (1972). Arte Poética IV. En Biblioteca Nacional de Portugal (2011), Sopbia de Mello Breyner Andresen no seu tempo: Momentos e Documentos (Selecção, conteúdos e organização por Maria Andresen Sousa Tavares). http://purl.pt/19841/1/ galeria/artes-poeticas/arte-poetica-iv.html

Andresen, S. (1989). Arte Poética V. En Biblioteca Nacional de Portugal (2011), Sophia de Mello Breyner Andresen no seu tempo: Momentos e Documentos (Selecção, conteúdos e organização por Maria Andresen Sousa Tavares). http://purl.pt/19841/1/ galeria/artes-poeticas/arte-poetica-v.html

Angenot, M. (1984). Glossário da Crítica Contemporânea. Comunicação.

Besse, Mª G. (1990). Sophia de Mello Breyner: Contos Exemplares. Publicações EuropaAmérica.

Ceia, C. (1996). Iniciação aos Mistérios da Poesia de Sophia de Mello Breyner Andresen. VEGA.

Ferreira, J. (2013). Ensaios sobre rumor de mar: temas da poesia de Sophia. Imprensa da Universidade de Coimbra.

Gomes, J. A. (2000). Sophia, infância e apelo do mar: elementos para uma leitura da obra para crianças. Contemporânea Editora.

Rocha, C. (2001). Para uma leitura dos Contos Exemplares. Mathesis, 10, pp. 73-84.

Martinho, F. J. B. (1991). Pessoa e a moderna poesia portuguesa: do Orpheu a 1960. Bertrand. 